\title{
Absolute Quantification of Tomato leaf curl New Delhi virus Spain strain, ToLCNDV-ES: Virus Accumulation in a Host-Specific Manner
}

\author{
Almudena Simón and Leticia Ruiz, IFAPA Centro La Mojonera, La Mojonera 04745, Almería, Spain; Leonardo Velasco, IFAPA Centro
} Churriana, Málaga 29140, Spain; and Dirk Janssen, ${ }^{\dagger}$ IFAPA Centro La Mojonera

\begin{abstract}
Tomato leaf curl New Delhi virus (ToLCNDV) (family Geminiviridae, genus Begomovirus) has recently been introduced in western Mediterranean countries. Isolates in Spain constitute a new strain, denominated ToLCNDV$\mathrm{ES}$, that is causing losses in commercial zucchini and melon crops; however, it is also, although less often, detected in commercial tomato crops. We developed a tissue-print hybridization test to detect the two genomic components of the virus and a TaqMan quantitative polymerase chain reaction (qPCR) test to estimate the number of genome copies in plants. qPCR was approximately $10^{4}$ to $10^{6}$ times more sensitive than tissue-print hybridization

to detect viral genomic DNA-A and DNA-B, respectively. It also detected the virus in more experimentally and naturally ToLCNDV-ES-infected zucchin squash and tomato plants. ToLCNDV-ES DNA-A titers were significantly lower in tomato than in zucchini plants, often falling below the detection limits in the hybridization test. In addition, the DNA-B accumulation was impaired in tomato when compared with zucchini. According to the data obtained in this study, the differences in viral titers of both plant species contribute to explain the dissimilarities in symptom expression, capability of detection, and transmission of the virus.
\end{abstract}

Tomato leaf curl New Delhi virus (ToLCNDV) is a bipartite species of genus Begomovirus (family Geminividae) with two circular singlestranded DNA genomic components of approximately $2.7 \mathrm{~kb}$ each, named DNA-A and DNA-B, which are encapsidated in geminate particles (Fauquet et al. 2008; Ito et al. 2008; Padidam et al. 1995). It is transmitted by the whitefly Bemisia tabaci and affects several crops from the Solanaceae and Cucurbitaceae families (Hussain et al. 2004; Pratap et al. 2011; Tiwari et al. 2012). ToLCNDV is responsible for significant yield losses in many crops (Kumar et al. 2008; Mansoor et al. 2006), and has become the most important tomato pathogen in India (Venkataravanappa et al. 2015). The virus has invaded other Asian countries such as Pakistan (Haider et al. 2006; Hussain et al. 2004), Bangladesh (Maruthi et al. 2005), Thailand (Ito et al. 2008), Indonesia (Mizutani et al. 2011), and Iran (Yazdani-Khameneh et al. 2016). Recently, the virus invaded the Mediterranean countries of Spain (Juárez et al. 2014), Tunisia (Mnari-Hattab et al. 2015), and Italy (Panno et al. 2016). The latest studies of ToLCNDV from Spanish isolates provided evidence that it is a new strain, designated ToLCNDV-ES, that may have evolved by recombination (Fortes et al. 2016; Ruiz et al. 2017). Symptoms produced by this strain in zucchini are curling, chlorosis, and vein thickening of leaves; stunted growth; and fruit deformation and abortion; whereas, in tomato, the symptoms of chlorosis and deformation in leaves are reminiscent of tomato yellow leaf curl disease (Ruiz et al. 2017).

The emergence of viruses is frequently associated with an increase of virulence (Anderson et al. 2004; Cleaveland et al. 2007; Longdon et al. 2015). In fact, ToLCNDV-ES has been reported as an important threat for cucurbit crops in Mediterranean countries, where it has recently emerged. In spite of that, field incidence and symptoms of ToLCNDV-ES are lower in tomato than in zucchini crops (Fortes et al. 2016; Ruiz et al. 2017).

\footnotetext{
${ }^{\dagger}$ Corresponding author: D. Janssen;

E-mail: dirk.janssen@juntadeandalucia.es
}

Disclaimer: Mention of trade names or commercial products in this publication is solely for the purpose of providing specific information and does not necessarily imply recommendation by the IFAPA.

*The $\boldsymbol{e}$-Xtra logo stands for "electronic extra" and indicates that four supplementary tables are published online.

Accepted for publication 29 August 2017.

C 2018 The American Phytopathological Society
Eradication or control of ToLCNDV-ES could be difficult due to its wide host range, its effective spread by whitefly, and its ability to evolve and adapt to new situations (Fortes et al. 2016; Ruiz et al. 2017). This issue is critical because the virus may invade crops species infected with other Begomovirus spp., leading to mixed infections with possible subsequent synergistic interactions or leading to new recombination events. In Spain, the virus is extensively detected in commercial zucchini and melon crops (Fortes et al. 2016; Juárez et al. 2014); Ruiz et al. (2015) reported on the presence of natural infections of ToLCNDV-ES in commercial tomato crops.

We designed and optimized a test to detect both DNA components of the virus genome based on tissue-print hybridization with digoxigenin (DIG)-labeled molecular probes. In addition, we developed a real-time quantitative polymerase chain reaction (qPCR) test using TaqManprobes, not only to detect but also to quantify ToLCNDV-ES DNA-A and DNA-B in experimental and natural infections of zucchini and tomato. Here, we found significantly different viral accumulations between both hosts, which could help to explain the differences in sensitivity to the virus.

\section{Materials and Methods}

Virus source, tissue prints, and DNA extraction. Leaf samples from 50 tomato and 45 zucchini squash plants showing symptoms reminiscent of ToLCNDV in natural infections were collected from commercial greenhouses in southern Spain during spring 2014. Viruliferous adult $B$. tabaci whiteflies, collected from ToLCNDV-symptomatic zucchini crops by means of a field aspirator and maintained on zucchini squash plants (Cucurbita pepo 'Victoria'), were used to infect 30 plants of Marmande tomato and 30 plants of zucchini squash (Victoria) in insectproof cages. The whiteflies were analyzed by reverse-transcription PCR to ensure the absence of cucurbit viruses transmitted by $B$. tabaci in Spain (Cucurbit yellow stunting disorder virus and Cucumber vein yellowing virus) (Ruiz et al. 2006) and by PCR to ensure the absence of tomato begomoviruses transmitted by B. tabaci (Tomato yellow leaf curl virus [TYLCV] and Tomato yellow leaf curl Sardinia virus [TYLCSV]) (Monci et al. 2002; Moriones et al. 1993; Navas-Castillo et al. 2011). The whitefly populations and inoculated plants were maintained in growth chambers at a controlled temperature of $25^{\circ} \mathrm{C}$ with a photoperiod of 16 and $8 \mathrm{~h}$.

Tissue prints from field and experimentally infected plants, as well as from healthy tomato and zucchini plants, were produced by transversely cutting leaf petioles and gently pressing the fresh cut onto duplicate, positively charged nylon membranes (EMD Millipore, Billerica, MA). After air drying, the membranes were irradiated with UV light $(50 \mathrm{~mJ})$ in a 
cross-linking oven. Total DNA from $0.1 \mathrm{~g}$ of fresh leaf tissue from ToLCNDV-infected and noninfected tomato and zucchini squash plants was extracted with DNeasy Plant Kit (Qiagen, Hilden, Germany), following the manufacturer's instructions. DNA concentrations were measured in duplicate with the UV-Vis spectrophotometer Nanodrop 2000c (Thermo Scientific, Waltham, MA). Aliquots were stored at $-20^{\circ} \mathrm{C}$ until use.

Preparation of standard samples. Dimeric ToLCNDV infectious clones of DNA-A and DNA-B were prepared as follows. Rolling circle amplification was performed on total DNA extracted and, after BamHI partial digestion, a 5.4-kb fragment was obtained, representing two full-length copies of the viral genome. The DNA fragments were recovered from agarose gel using a Zymoclean Gel DNA Recovery kit (Zymo Research, Irvine, CA), cloned into an BamHIlinearized pUC19 (Addgene; New England BioLabs, Beverly, MA), and used to transform Escherichia coli XL1-BLUE (Agilent Technologies Inc., Santa Clara, CA) competent cells. The resulting plasmids, pUC2TOA4R and pUC2TOB14R, contained complete dimers for DNA-A and DNA-B, respectively, and were recovered from bacterial cultures using the Zyppy Plasmid Miniprep Kit (Zymo Research). After sequencing with specific primers, the correctness of the inserts was confirmed by comparison with sequences available in the databases (GenBank accession numbers KM977733 and KT175406 for DNA-A and KM977734 and KT175407 for DNAB). In addition, the integrity of double-stranded circular molecules containing $2 \times$ DNA-A and DNA-B was analyzed by gel electrophoresis in $1 \%$ agarose gels and quantified with a NanoDrop 2000c spectrophotometer (Thermo Scientific) to assess purity through determination of the ratio of absorbance at $260 / 280 \mathrm{~nm}$, and to estimate the yield.

Design of probes and primers. All primers and probes for tissueprint hybridization and qPCR were designed in silico, based on the genome sequences from the identified Spanish isolates of ToLCNDV and available in GenBank (Table 1). For the molecular hybridization assay, two primer sets were designed from the $A V 1$ (coat protein) and $B V 1$ (nuclear shuttle protein) gene sequences located on DNA-A and DNA-B, respectively, using the Primer Blast tool (https://www.ncbi. nlm.nih.gov/tools/primer-blast/). For qPCR, two set of primers and two dual-labeled TaqMan probes were designed from the AV2 (movement protein) and $B C 1$ (movement protein) gene sequences located on DNA-A and DNA-B, respectively (Table 1). Probes and primers were designed and assessed for compatibility using Beacon Designer 7.91 software (Premier Biosoft, Palo Alto, CA). Four primers were used to amplify a 106-nucleotide (ToLA-Up and ToLA-Low) and 119-nucleotide (ToLB-Up and ToLB-Low) fragment. TaqMan probes ToLA-probe and ToLB-probe were used for detection in qPCR. The TaqMan probes were labeled with 6-carboxyfluorescein and 4-5-dichloro carboxy fluorescein at the $5^{\prime}$ terminal and fluorescent quencher (6-carboxy tetramethyl rhodamine) at the $3^{\prime}$ terminal. Primers and probes were synthesized by Sigma-Aldrich (St. Louis). In silico analysis of ToLCNDV-ES specificity was ensured with respect to other whitefly-transmitted monopartite begomoviruses in tomato (TYLCV and TYLCSV) for all primers and probes with the online software "PCR products", accessible through SMS (http://www.bioinformatics.org/sms2/pcr_products.html).

Preparation of DIG-labeled probes and tissue-print hybridization optimization. PCR amplifications from the partial $A V 1$ gene and $B V 1$ gene were obtained from zucchini squash-infected plants using the primer pairs ToNDA-580F, ToNDA-935F, ToNDB600F, and ToNDB-1080R (Table 1). PCR were done as follows. Total DNA ( $2 \mu \mathrm{l}$, approximately $1 \mu \mathrm{g})$ was amplified in a $25-\mu 1$ reaction mixture containing PCR buffer, $1.25 \mathrm{mM} \mathrm{MgCl}_{2}, 10 \mathrm{mM}$ four dNTP mixtures, $10 \mu \mathrm{M}$ primers, $2.5 \mathrm{U}$ of Go Taq DNA polymerase (Promega Corp., Madison, WI), and $11.75 \mu \mathrm{l}$ of nuclease-free water. The thermal cycling conditions were $95^{\circ} \mathrm{C}$ for $2 \mathrm{~min}$; followed by 35 cycles of $95^{\circ} \mathrm{C}$ for $30 \mathrm{~s}, 55^{\circ} \mathrm{C}$ for $30 \mathrm{~s}$, and $72^{\circ} \mathrm{C}$ for $50 \mathrm{~s}$; followed by a final extension for $5 \mathrm{~min}$ at $72^{\circ} \mathrm{C}$. PCR products were ligated into pGEM-T Easy vector (Promega Corp.) according to the manufacturer's instructions and transformed into DH5 $\alpha$ E. coli cells. The plasmid inserts were sequenced and the identity was confirmed as described above.

DIG-labeled probes were prepared by PCR containing $200 \mathrm{ng}$ of linearized pGEM-T-cp-AV1 or pGEM-T-nsp-BV1 plasmid, using the PCR DIG Labeling Mix (Roche Diagnostics, Rotkreuz, Switzerland) and following the manufacturer's instructions. Thermocycling conditions were identical to those described above.

For detection of ToLCNDV by molecular DIG-labeled probe hybridization, sap samples were used, bound by tissue print on the duplicated positively charged nylon membranes, one for DNA-A and one for DNA-B, with three replicates per sample. Prehybridization was carried out for $2 \mathrm{~h}$ at $55^{\circ} \mathrm{C}$ followed by overnight hybridization with DIG-labeled probes at $10 \mathrm{ng} / \mathrm{ml}$ and $55^{\circ} \mathrm{C}$. The hybridization solution contained $5 \times \mathrm{SSC}(20 \times \mathrm{SSC}=3 \mathrm{M} \mathrm{NaCl}$ and $0.3 \mathrm{M}$ sodium

Table 1. Primers and probes used for tissue-print hybridization and quantitative polymerase chain reaction in this study

\begin{tabular}{|c|c|c|c|c|c|}
\hline Name & Nucleotide sequence $\left(5^{\prime}-3^{\prime}\right)^{a}$ & Position $^{b}$ & Size $(b p)^{c}$ & Gene & Reference \\
\hline \multirow[t]{3}{*}{ ToNDA-580F } & TCACACATCGCGTAGGCAAG & $580-600$ & 400 & $A V 1$ & KF749224 \\
\hline & $\ldots$ & $\ldots$ & $\ldots$ & $\ldots$ & KF749225 \\
\hline & $\ldots$ & $\ldots$ & $\ldots$ & $\ldots$ & KF749223 \\
\hline \multirow[t]{2}{*}{ ToNDA-935R } & TGCCGGCCTCTTGTTGATTG & $935-915$ & $\ldots$ & $\ldots$ & KF891468 \\
\hline & $\ldots$ & $\ldots$ & $\ldots$ & $\ldots$ & KM977733 \\
\hline \multirow[t]{3}{*}{ ToNDB-600F } & AATATACGCGTAAGGAAATCTGT & $600-623$ & 480 & $B V 1$ & KF749226 \\
\hline & $\ldots$ & $\ldots$ & $\ldots$ & $\ldots$ & KF749227 \\
\hline & $\ldots$ & $\ldots$ & $\ldots$ & $\ldots$ & KF749228 \\
\hline \multirow[t]{2}{*}{ ToNDB-1080R } & GTTGTGTAMGTTCTTGGGATGC & $1,080-1,058$ & $\ldots$ & $\ldots$ & KF891467 \\
\hline & $\ldots$ & $\ldots$ & $\cdots$ & $\cdots$ & KM977734 \\
\hline \multirow[t]{2}{*}{ ToLA-Up } & CATTATTGCACGAATTTCCG & $129-148$ & 109 & $A V 2$ & KF749224 \\
\hline & $\ldots$ & $\ldots$ & $\ldots$ & $\ldots$ & KF749225 \\
\hline ToLA-Low & ATCGTAGCCGACTGTGTCTG & $238-219$ & $\ldots$ & $\ldots$ & KF749223 \\
\hline \multirow[t]{2}{*}{ ToLA-Probe } & (JOE)CATGCACCTTAGACCATGGACGCT(TAM) & $175-151$ & $\ldots$ & $\cdots$ & KF891468 \\
\hline & $\ldots$ & $\ldots$ & $\ldots$ & $\ldots$ & KM977733 \\
\hline \multirow[t]{2}{*}{ ToLB-Up } & TCCGACAGCATTAATTGGAA & $1,923-1,942$ & 116 & $B C 1$ & KF749226 \\
\hline & $\ldots$ & $\ldots$ & $\ldots$ & $\ldots$ & KF749227 \\
\hline ToLB-Low & GAACGATGCTGCAGAGGTAA & $2,058-2,039$ & $\ldots$ & $\ldots$ & KF749228 \\
\hline \multirow[t]{2}{*}{ ToLB-Probe } & (6FAM)TGCACCTGTTCCTCAGCTGGC(TAM) & $1,982-2,002$ & $\ldots$ & $\ldots$ & KF891467 \\
\hline & $\ldots$ & $\ldots$ & $\ldots$ & $\ldots$ & KM977734 \\
\hline
\end{tabular}


citrate, $\mathrm{pH} 7$ ), $0.02 \%$ sodium dodecyl sulfate (SDS), $0.1 \%$ sodium $\mathrm{N}$-lauroylsarcosine, $2 \%$ blocking reagent, and $50 \%$ deionized formamide (Roche Diagnostics). The membranes were washed under stringent condition: $2 \times \mathrm{SSC}, 0.1 \% \mathrm{SDS}$ for $5 \mathrm{~min}$ at room temperature followed by two washes of $15 \mathrm{~min}$ each in $0.1 \times \mathrm{SSC}, 0.1 \%$ SDS at $68^{\circ} \mathrm{C}$. Next, the membranes were washed with maleate buffer $(0.1 \mathrm{M}$ maleic acid and $0.15 \mathrm{M} \mathrm{NaCl}, \mathrm{pH} 7.5$ ) plus $0.3 \%$ Tween 20 for $5 \mathrm{~min}$ at room temperature, then incubated with $1 \%$ blocking reagent buffer, followed by anti-DIG antibody conjugated with alkaline phosphatase (Antidigoxigenin-AP Fab fragments) (Roche Diagnostics, GmbH, Mannheim, Germany), and, finally, washed with maleate buffer plus $0.3 \%$ Tween 20. Detection by chemiluminescence was carried out with CSPD (Roche Diagnostics, GmbH) following the manufacturer's instructions and different times of exposure (15 min, $2 \mathrm{~h}$, or overnight) at room temperature to a Lumi-film (Amersham Bioscience, Little Chalfont, UK).

The specificity of the probes was tested against different healthy and infected plant tissue. Additionally, to ensure ToLCNDV specificity, empirical parameters such as different prehybridization and hybridization temperatures were evaluated to avoid a possible TYLCV or TYLCSV cross reactivity in tomato samples. Furthermore, 10fold serial dilutions of standard samples (ToLCNDV dimeric clones of DNA-A and DNA-B) were used to evaluate tissue-printing sensitivity.

qPCR and quantitative analyses. qPCR was performed in a ABI PRISM 7000 Sequence Detection System (Applied Biosystems, Foster City, CA), using $25 \mu \mathrm{l}$ of a reaction mix that contained $12.5 \mu \mathrm{l}$ of TaqMan Universal PCR Master Mix (Applied Biosystems), $10.75 \mu \mathrm{l}$ of nuclease-free water, $50 \mathrm{nM}(0.05 \mu \mathrm{M})$ each forward and reverse primer, $50 \mathrm{nM}(0.05 \mu \mathrm{M})$ TaqMan probe, and $1 \mu \mathrm{l}$ of total DNA (10 ng) $(0.01 \mu \mathrm{g})$ for each genomic component of ToLCNDV. Cycling conditions consisted of incubation at $95^{\circ} \mathrm{C}$ for $10 \mathrm{~min}$ and 40 cycles of $95^{\circ} \mathrm{C}$ for $15 \mathrm{~s}$ and $60^{\circ} \mathrm{C}$ for $1 \mathrm{~min}$. In each run, the ABI Prism 7000 SDS 1.2.3 software plotted the fluorescence intensity against the number of cycles and provided the quantification cycle $(\mathrm{Cq})$ value.

ToLCNDV dimeric clones of DNA-A and DNA-B were used as standards for quantitative analyses. Conversion of double-stranded DNA (dsDNA) to nanograms was performed considering the average molecular weight of a base pair of deoxynucleotide $(650 \mathrm{Da})$ and the recombinant DNA base pair number. Avogadro's constant $(6.023 \times$ $10^{23}$ molecules $/ \mathrm{mol}$ ) was used to estimate the dsDNA copy number. To generate external standard curves for absolute quantification, 10-fold serial dilutions containing circular dsDNA at $10^{9}$ to $10^{\circ}$ molecules/ $\mu l$ of each viral genomic component were prepared and analyzed by qPCR with the two designed probes: ToLAProbe (AV2 gene) and ToLB-Probe (BC1 gene) (Table 1). Total DNA extracts without viral DNA from healthy plants of zucchini squash and tomato were run in parallel to ensure the absence of any ToLCNDV amplification. Standard curves for each TaqMan probe were constructed, plotting $\mathrm{Cq}$ values per three replicates per standard dilution versus the DNA copy number logarithm. The amplification efficiency was calculated from the slope of the corresponding curve using the formula $\left(10^{(-1 / \text { slope of the standard curve })}-\right.$ 1) $\times 100$ (percent values). Quantification of each DNA was obtained by interpolation of $\mathrm{Cq}$ data with the corresponding standard curve. Data from dsDNA quantification was multiplied by two because each dsDNA clone molecule contains two dsDNA genome copies. Moreover, to ensure the specificity of designed primers and probes, total DNA extracts from tomato plants with single infections of TYLCV or TYLCSV and plants coinfected with ToLCNDV-ES were assayed.

In order to evaluate the qPCR assay repeatability and reproducibility, the 10-fold serial dilutions of each standard sample, containing circular dsDNA at $10^{9}$ to $10^{\circ}$ molecules/ $\mu$, were analyzed in triplicate and in three independent qPCR runs. Furthermore, 10 -fold serial dilutions of DNA extracts from infected plants of zucchini squash and tomato were used to prepare dilution curves for both viral genomic components in each case. The efficiency variation and accuracy were compared between both types of templates, standards, and extracts of total nucleic acids (TNA) from ToLCNDV-infected plants, obtained as described by Mason et al. (2008). The Cq mean values and standard deviation (SD), correlation coefficients, and calculated amplification efficiencies across the entire linear dynamic range assayed were calculated for every condition.

ToLCNDV genome copy numbers in tomato and zucchini. The developed qPCR assay was tested for detection and absolute quantification of ToLCNDV in zucchini squash and tomato plants. These samples were collected from biological inoculation assays and from commercial and naturally infected greenhouses. Total DNA extracts $(10 \mathrm{ng})$ from symptomatic and asymptomatic leaves were tested as described above. Each sample was analyzed in triplicate and the mean $\mathrm{Cq}$ and its SD were calculated. Every Cq mean value was extrapolated on the corresponding standard curve. The ToLCNDV copy number was calculated from the formula $10^{\text {(Cq-b/slope of the standard curve) }}$, where $\mathrm{b}$ is the y intercept.

ToLCNDV-ES infection following whitefly transmission. For monitoring the ToLCNDV-ES infection using whiteflies among zucchini and tomato, a virus-free population of $B$. tabaci was reared on eggplant (Solanum melongena 'Crisol') and adult whiteflies were taken for transmission studies. Marmande tomato and Victoria zucchini squash plantlets were sap inoculated (López et al. 2015) at the two- or three-true-leaf stage and used as the virus source. Groups of five target plants of the same cultivar of tomato and zucchini squash source plants were used as the test plant for the ToLCNDV-ES systemic infection studies. Groups of healthy whiteflies (approximately 50) were given a 48-h acquisition access period on previous sap-inoculated plants and released on target plants with two or three developed leaves for a 72-h inoculation access period. After that, the whiteflies were chemically eliminated. Whiteflies that were allowed to feed on healthy zucchini squash and tomato plants served as a negative control. The whitefly populations and inoculated plants were maintained in growth chambers at a controlled temperature of $25^{\circ} \mathrm{C}$ with a photoperiod of 16 and $8 \mathrm{~h}$. Leaf tissue was removed from the plants at 10,20, and 30 days postinoculation (dpi) to determine the absolute amounts of viral genomic components.

Statistical analysis. The methods concordance (agreement degree between results from tissue-print hybridization and qPCR) was evaluated after testing the same plant samples in both tests and comparing their sensitivities in the Fisher's test $(<0.05)$ with $95 \%$ confidence interval. To determinate qPCR sensitivity relative to tissue printing (the fraction of plant samples with ToLCNDV-ES correctly detected as positive by the test) and its specificity (the fraction of healthy plants correctly identified as negative by the test), samples of 30 zucchini squash and 30 tomato plants from biological inoculation assays and 45 zucchini and 50 tomato plants from commercial greenhouses were analyzed using both procedures.

The difference of slopes from standards curves and from total plant DNA extracts was analyzed by the $F$ test. The differences between the viral genome copy numbers from experimentally and naturally infected plants were analyzed with the Mann-Whitman $U$ test. All these tests were performed using Graph Prism 7.0 analytical software (La Joya, CA). Comparison of pooled data from DNA-A and DNA-B copy numbers in tomato and zucchini was subjected to Hotelling's $T^{2}$ test using the Real Statistics Resource Pack software (release 4.3; Charles Zaiontz, www.real-statistics.com).

\section{Results}

Optimization and sensitivity of qPCR and tissue-print hybridization. Following the manufacturer's recommendations, the concentrations of the probes in real-time PCR were fixed initially at $250 \mathrm{nM}$. The qPCR primers were tested at 50, 300, and $900 \mathrm{nM}$ each, in a three-by-three matrix. The optimum concentration was found to be $50 \mathrm{nM}$ for both forward and reverse primers ( $A V 2$ and $B C 1$ genes). Next, different TaqMan probe concentrations were compared in qPCR and were determined to be optimal for the detection of the DNA-A and DNA-B targets sequences at a concentration of $50 \mathrm{nM}$.

The two standard curves, containing $10^{\circ}$ to $10^{9}$ copies for each genomic component, covered a wide dynamic range of eight log units of concentration. Even though this procedure enabled detection of as few as $10^{2} A V 2$ gene copies, the quantification of such a low number 
was not reliable because it fell off the linear range of the standard curve. Consequently, the limit of detection (LOD) was fixed at $10^{3}$ copies for DNA-A and $10^{2}$ copies for DNA-B (Fig. 1).

The intraassay $\mathrm{Cq}$ variability, as the SD from three qPCR replicas of every standard dilution, was very low-from 0.01 to 0.69 for $A V 2$ and 0.12 to 0.77 for $B C 1$ genes - which suggests a high repeatability of quantification for both viral genomic components. In addition, three independent interassay standard curves for each genomic component showed a low $\mathrm{Cq}$ variation, with correlation coefficients greater than 0.99 and amplification efficiencies of $97.9 \%$ for DNA-A and $96.2 \%$ for DNA-B, making the assays highly reproducible. Repeatability and reproducibility of data were accurate in the dynamic ranges described above for each genomic component (Fig. 1).

On the other hand, in order to determine LOD and evaluate the intra- and interassay variability of the tissue-printing test, the standard serial dilutions were also tested by the designed procedure, containing $10^{\circ}$ to $10^{9}$ copies for each component with three independent replicas and for three independent assays. This enabled the detection of $10^{8}$ DNA-A and DNA-B copies.

As for the methods specificity, total DNA extracts from healthy zucchini squash and tomato plants and extracts from tomato in single TYLCV or TYLCSV infection and ToLCNDV + TYLCV or TYLCSV coinfections were tested. Positive results were only found for plant samples infected with ToLCNDV-ES and negative results for healthy plants and those with single TYLCV or TYLCSV infections. In tissue printing, a temperature gradient from 68 to $42^{\circ} \mathrm{C}$ for prehybridization and hybridization steps was assayed in order to determine the possibility of cross reactions with the mentioned monopartite begomoviruses. Fixing the temperature for prehybridization and hybridization at $55^{\circ} \mathrm{C}$ permitted the detection of ToLCNDV-ES and avoided cross-reactions with TYLCV or TYLCSV. These temperature conditions also allowed virus detection in infected zucchini squash plants.

Eventually, evaluations of qPCR specificity, sensitivity, and precision were performed through dilution curves, which were based on total DNA extracts of infected samples. For each host, 10-fold serial dilutions of TNA $(1.57 \mu \mathrm{g}$ to $0.1572 \mathrm{fg}$ from a zucchini squash plant and $1.315 \mu \mathrm{g}$ to $0.1315 \mathrm{fg}$ from a tomato plant) were amplified by qPCR. For both genomic components, there were no statistically significant differences in the slope values between the standards and TNA extracts from infected zucchini and tomato plants. The TNA amplification efficiency of the $A V 2$ gene was slightly higher (115.8\% in zucchini squash and $112.2 \%$ in tomato) than the standard (97.87\%). The amplification efficiency for the $B C l$ gene of the zucchini squash TNA extract was also slightly higher (102.4\%) and rather similar in the tomato TNA extract $(97.1 \%)$, in comparison with the amplification efficiency of the standard (96.9\%). These qPCR assays detected as few $2.67 \times 10^{2}$ copies of $A V 2$ DNA-A in zucchini squash and $9.39 \times 10^{2}$ in tomato, and $2.47 \times 10^{3}$ and $3.45 \times 10^{2}$ copies of $B C 1$ TNA extracts of zucchini squash and tomato, respectively.

For $A V 2$ gene quantification in zucchini squash, the last dilution point $(0.1572 \mathrm{fg})$ was detected with a $\mathrm{Cq}$ of $39.42 \pm 0.75$ but was considered negative. The reaction, which contained $1.572 \mathrm{fg}$ of template, yielded a Cq of $36.87 \pm 0.67$, which corresponded to $1.52 \times 10^{3} A V 2$ gene copies, whereas $0.687 \mathrm{fg}$ of the standard corresponded to $7.80 \times$ $10^{2}$ copies. However, in tomato, the last dilution point was undetermined; the reaction, which contained $135 \mathrm{pg}$ of template, yielded a $\mathrm{Cq}$ of $37.58 \pm 0.67$. This corresponded to $9.39 \times 10^{2}$ AV2 gene copies. For $B C 1$ gene amplification in zucchini squash, the last dilution point, which contained $0.1572 \mathrm{fg}$ of template, yielded a Cq of $34.43 \pm$ 0.30 , which corresponded to $2.47 \times 10^{3}$ copies, whereas $0.83 \mathrm{fg}$ of the standard corresponded to $9.51 \times 10^{2} \mathrm{BCl}$ gene copies. In tomato, the dilution point contained $135 \mathrm{pg}$ of template and had a Cq of $37.34 \pm$ 0.82 , which corresponded to $3.45 \times 10^{2}$ copies and $827 \mathrm{pg}$ of the standard corresponded to $9.51 \times 10^{4} \mathrm{BC} 1$ gene copies. Taking into account that a TNA reaction may contain inhibitors and likely chemical carryover in comparison with the higher purity of the plasmid solution, the difference in sensitivity between each template could be normal. Therefore, TNA results could be more similar to the routine conditions for ToLCNDV-ES detection assays.

Altogether, these results indicate that the procedure was robust and reliable; even in the presence of large amounts of nonspecific DNA, the test can be used to detect and estimate the number of copies in both ToLCNDV-ES genomic components in a specific and sensitive manner.

Comparison of sensitivity between tissue-print hybridization and qPCR and methodological concordance. In order to compare the end-point sensitivity between tissue-print hybridization and TaqMan qPCR, the standard 10-fold serial dilutions were assayed simultaneously. Thus, for DNA-A, the tissue-printing detection threshold was found to be $7.80 \times 10^{7}$ copies $(0.687 \mathrm{ng})$ whereas, by qPCR, $7.80 \times 10^{3}$ copies $(6.87 \mathrm{fg})$ could be detected. For DNA-B, $9.51 \times 10^{7}$ copies $(0.827 \mathrm{ng})$ and $9.51 \times 10^{1}$ copies $(0.827 \mathrm{fg})$ were detected by tissue-printing and qPCR, respectively.

It was concluded that the qPCR assay was approximately $10^{4}$ times more sensitive to detect ToLCNDV-ES DNA-A than tissue-print hybridization and $10^{6}$ times for ToLCNDV-ES DNA-B.

On the other hand, the performance of the different designed probes (Table 1) and procedures were validated using crude sap or total DNA extracted from ToLCNDV-ES-infected plants of tomato and zucchini squash as a template. Some samples, whose full genomic component nucleotide sequences were known, were inoculated by $B$. tabaci under controlled conditions (Supplementary Table S1). Others were collected from commercial greenhouses (Supplementary Tables S2 and S3). Tissueprint hybridization and qPCR using crude sap or total DNA extracts from healthy plants gave negative results. Among a total of 155 samples, 139

\section{ToLCNDV-ES (DNA-A)}

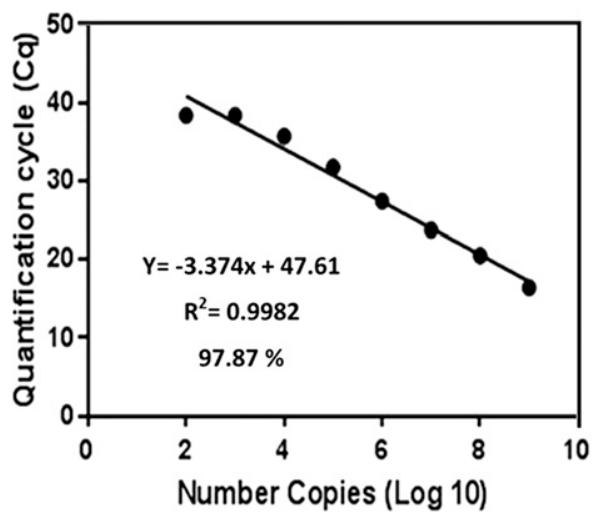

\section{TOLCNDV-ES (DNA-B)}

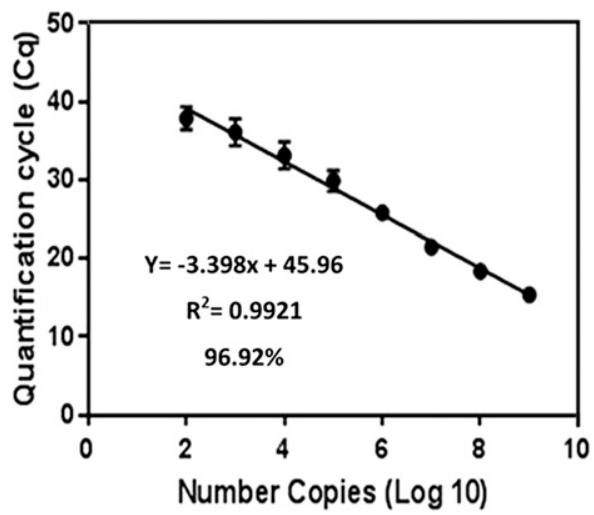

Fig. 1. Evaluation of amplification efficiency and dynamic range of amplification of the target (AV2 and $B C 1$ genes) specific DNA templates. Mean quantification cycle values were obtained from serial $\log _{10}$ dilutions of dimeric clones of ToLCNDV-ES DNA-A and DNA-B as standards. The figure shows the regression function, coefficient of correlation, and efficiency values obtained. Bars represent standard deviation. 
Table 2. Tomato leaf curl New Delhi virus, Spanish strain detection in samples of zucchini squash and tomato from biological assays and commercial greenhouses evaluated in this study by tissue-print hybridization and quantitative polymerase chain reaction ( $\mathrm{PPCR}$ )

\begin{tabular}{lcccc}
\hline & \multicolumn{3}{c}{ Number of samples } & \\
\cline { 2 - 4 } Host & Total & $\begin{array}{c}\text { Tissue-print } \\
\text { hybridization }\end{array}$ & qPCR $^{\mathbf{b}}$ & Concordance (\%) \\
\hline Zucchini squash & 75 & 59 & 74 & $59 / 74(79.73)$ \\
Tomato & 80 & 8 & 65 & $8 / 65(12.31)$ \\
Total & 155 & 67 & 139 & $67 / 139(48.20)$ \\
\hline
\end{tabular}

a Positive samples by tissue-print hybridization.

b Positive samples by qPCR.

${ }^{c}$ Results of individual samples diagnosed by tissue-print hybridization and qPCR were compared. Comparisons were analyzed by Fisher's test with 95\% confidence interval. The difference was statically significant, $P$ values < 0.0001 were detected as positive by qPCR, whereas only 67 samples were positive by tissue-printing, supposing a relative sensitivity and specificity of 100 and $18.18 \%$, respectively, for qPCR. Consequently, the two assays' concordance for individual leaf tests was more than $48 \%$ (Table 2). Statistically significant differences between the sensitivities of both tests were established through Fisher's test and yielded a $P$ value $<0.0001$. These results showed that, overall, qPCR yielded more accurate findings and detected more samples of infected plants when the virus titer was low in tomato compared with tissue-print hybridization.

ToLCNDV-ES absolute quantification and its host relationship. All Cq values obtained from qPCR for DNA-A and DNA-B samples were within the dynamic range of the respective standard curves. The copy numbers of $A V 2$ and $B C 1$ genes of ToLCNDV-ES in infected zucchini and tomato ranged between $7.15 \times 10^{2}$ and $3.14 \times 10^{9}$ (DNA-A) and between $3.50 \times 10^{2}$ and $1.19 \times 10^{9}$ (DNA-B). The mean number of genome copies was $3.82 \times 10^{6}(A V 2$ gene $)$ and $4.18 \times 10^{6}(B C 1$ gene $)$

\section{ToLCNDV-ES}

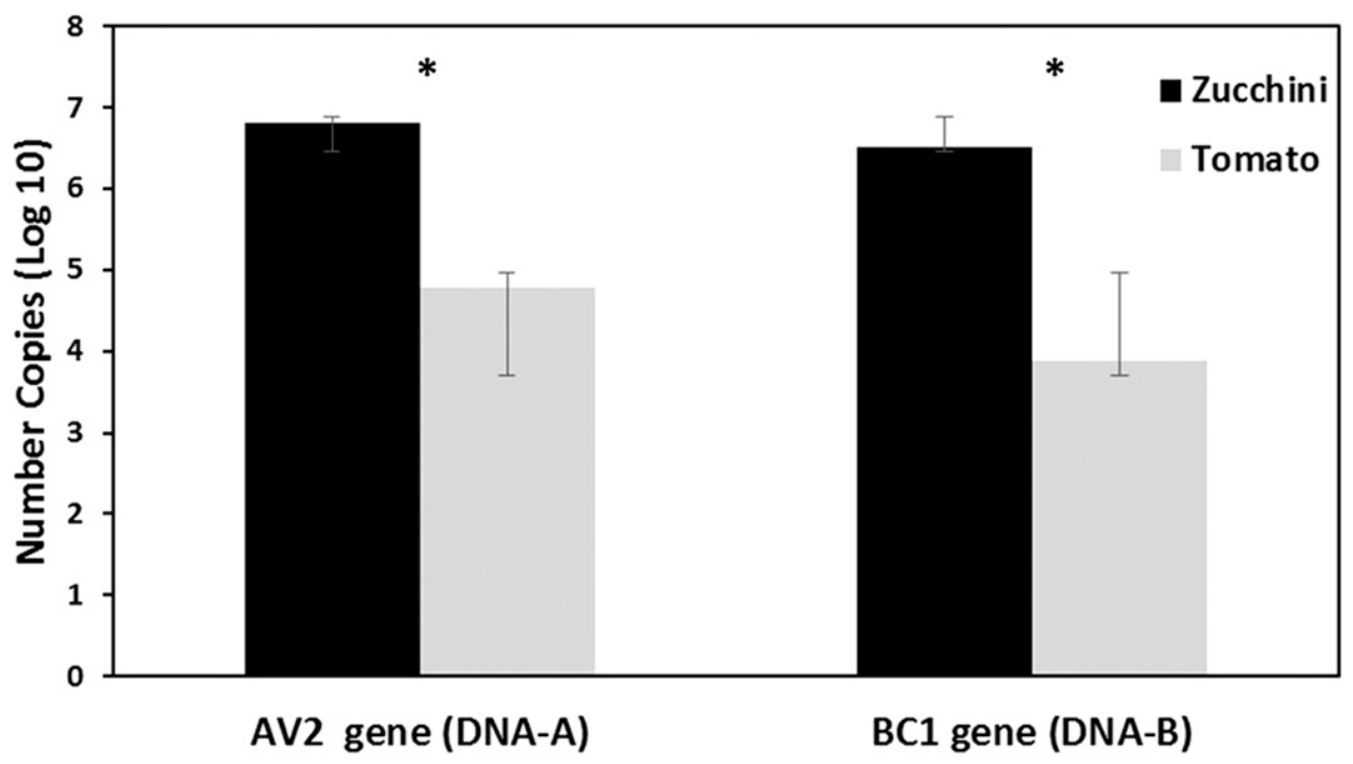

Fig. 2. ToLCNDV-ES mean copy numbers for both genomic components and in each host evaluated (zucchini squash and tomato) from experimental and natural infections Statistically significant differences of viral titer for both DNA amid hosts are marked with an asterisk $\left(^{*}\right)\left(T^{2}\right.$ Hotelling $\left.=108.39, F=53.77, \mathrm{df}=2,113, P<0.0001\right)$. Error bars represent standard deviation.

\section{ToLCNDV-ES Infection}

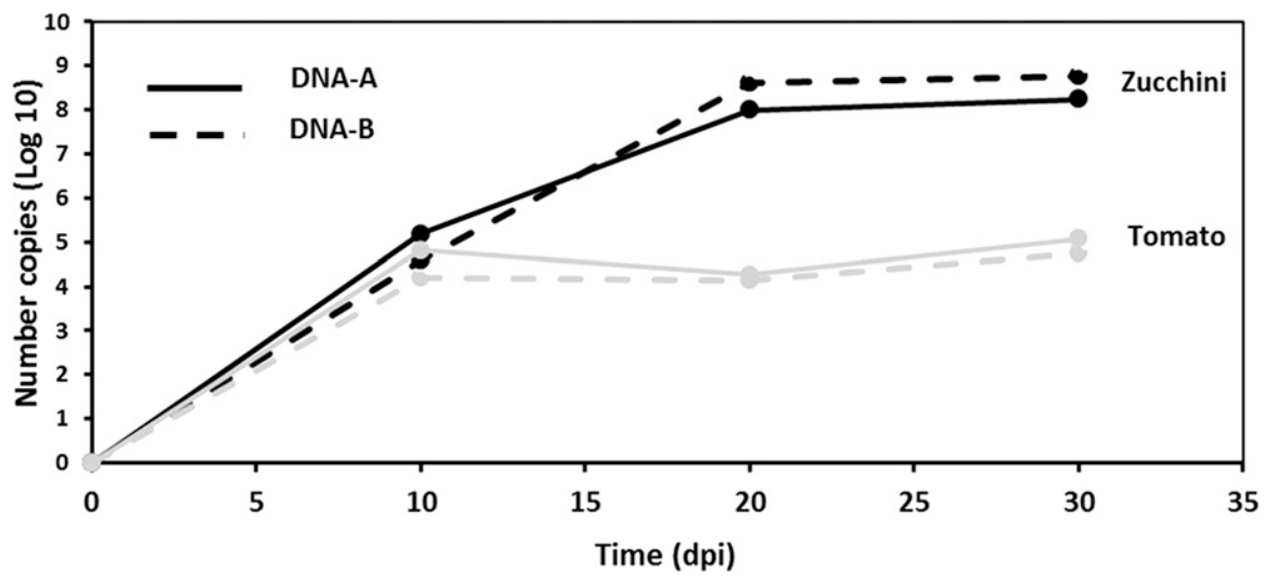

Fig. 3. Absolute quantification of ToLCNDV-ES genomic components during systemic tomato and zucchini infection. Plants with two or three developed leaves were inoculated with infected Bemisia tabaci populations. Tissue from symptomatic apical leaves was collected at 10, 20, and 30 days postinoculation (dpi). Equal amounts of extracted DNA (10 ng/ $\mu$ l) collected at each time point from five target plants from each experiment were analyzed and the viral titer was determined by quantitative polymerase chain reaction. Values represented correspond to the mean copy number $\left(\log _{10}\right)$ of ToLCNDV-ES. 
in samples from experimentally infected zucchini squash whereas, in the case of tomato, the mean numbers were lower: $5.23 \times 10^{4}$ (AV2 gene) and $5.46 \times 10^{3}$ ( $B C 1$ gene). Similarly, the copy numbers found in naturally infected zucchini squash were $9.66 \times 10^{6}\left(A V 2\right.$ gene) and $2.80 \times 10^{6}$ $\left(B C 1\right.$ gene), and $7.04 \times 10^{4}$ ( $A V 2$ gene) and $1.10 \times 10^{4}(B C 1$ gene) in the case of tomato. Within each host species, there were no differences in terms of ToLCNDV-ES accumulation between experimentally and naturally infected plants (Mann-Whitney $U$ test, $P$ values $>0.05$; zucchini squash DNA-A, $P=0.2950$, and DNA-B, $P=0.9751$; tomato DNA-A, $P=0.9012$, and DNA-B, $P=0.3779$ ). The mean copy numbers of both genomic components were approximately $10^{2}$ times higher in zucchini squash compared with tomato $\left(T^{2}\right.$ Hotelling test, $\left.P<0.0001\right)$ (Fig. 2). Also, the amounts of ToLCNDV-ES DNA-A and DNA-B in zucchini were correlated and within the same range $(\rho=0.8865, P<0.0001)$ but were not so in the case of tomato $(\rho=0.2595, P=0.0513)$ (Spearman test).

ToLCNDV-ES DNA titers of during zucchini squash and tomato infection. Following whitefly transmission of ToLCNDVES, the titer in zucchini and tomato was compared at 10, 20, and 30 dpi using qPCR. At the earlier stage of the infection (10 dpi), the amounts of DNA-A and DNA-B were similar in zucchini and in tomato. At the latter stages (20 and $30 \mathrm{dpi})$, the DNA-A and DNA-B amounts remained in the same magnitude order $\left(10^{4}\right.$ to $\left.10^{5}\right)$ in tomato; in contrast, they were significantly higher, up to $10^{3}$ (DNA-A) and $10^{4}$ (DNA-B) in zucchini, reaching maximum values at 30 dpi of $6.42 \times 10^{8}$ and $7.57 \times 10^{8}$ copies, respectively (Fig. 3; analysis of variance test, $P=0.0002$ [DNA-A] and $P<0.0001$ [DNA-B]) (Supplementary Table S4). In the present studies, the tomato plants developed symptoms but continued to grow, whereas many of the zucchini plants died after 1 month of infection.

\section{Discussion}

The bipartite begomovirus ToLCNDV-ES infects cucurbit and tomato crops species but the symptoms produced are typically severe in zucchini and milder in tomato (Ruiz et al. 2017). We designed and validated two molecular detection techniques to investigate and compare the virus in both host species. A tissue-print hybridization, described in the present article, consistently underestimated the presence of the virus in tomato. Our test, using DIG-labeled DNA-probes specific for the virus, did not cross-react with monopartite TYLCV and TYLCSV. Its LOD was at the $10^{-1}$ dilution, which represented $10^{8}$ molecules of ToLCNDV-ES of each genomic component. Recently, a nucleic acid spot hybridization test (NASH) using riboprobes against ToLCNDV has been described (Alfaro-Fernández et al. 2016) but a lack of information about the starting amounts used makes it difficult to compare the sensitivity of the tests. Because the NASH technique requires nucleic acids extraction (silica or EZNA) (Alfaro-Fernández et al. 2016), the tissue-print hybridization presented here provided a simpler and faster alternative.

Although the LOD of target DNA in qPCR or in tissue printing cannot be directly compared, the amounts of the genome copy numbers make us suspect that the lower concentration of ToLCNDV-ES genome components in tomato may compromise the reliable detection using hybridization with DIG-labeled DNA probes. This would explain why both detection techniques correlated well in zucchini but not in tomato (Table 2). Instead, TaqMan qPCR was able to detect and quantify ToLCNDV-ES and proved to be highly specific and sensitive enough to detect as few as $7.8 \times 10^{2}$ units of DNA-A and $9.51 \times 10^{1}$ units of DNA-B. These LOD values were similar to those reported for TYLCV, TYLCSV, Squash leaf curl virus, and other virus species (Debreczeni et al. 2011; Kuan et al. 2012; Rodríguez-Negrete et al. 2014).

The comparison of both techniques for ToLCNDV-ES detection, as described in this work, revealed that qPCR had a sensitivity that was $10^{4}$ times higher than that of tissue printing for DNA-A and $10^{6}$ for DNA-B, comparable with differences reported between molecular and serological detection methods for other virus species (Liu et al. 2013; Mason et al. 2008). Furthermore, taking into account the number of samples analyzed in this study, the concordance correlation value was $49 \%$, meaning that almost half of the samples identified by qPCR were also recognized in tissue-print tests; in addition,
qPCR enabled detection of $18.8 \%$ of the samples that were identified as negative in tissue-print hybridization. This value increased noticeably to $79.73 \%$ when only zucchini squash samples were considered, suggesting the presence of inhibitors in tomato or a different disease susceptibility (discussed above) (Table 2).

Using TaqMan-qPCR, we found that ToLCNDV-ES genome titers were lower in tomato than in zucchini plants, and this was observed in both natural and experimental infections (Figs. 2 and 3). Viral titers in natural or experimental ToLCNDV-ES infections using whitefly transmissions ranged similarly for each of the host species object of this work. In tomato, when the transmission was performed using B. tabaci, the ratio of genomic DNA-A and DNA-B did not differ significantly between early and subsequent stages of the infection (Fig. 2). Comparative results have been described for the same host; for example, after agroinoculation with the ToLCNDV type strain (Kanakala et al. 2013) or Potato yellow mosaic virus (Péréfarres et al. 2011), it has been suggested that this DNA-A/DNA-B ratio ensured an optimal virus replication.

Virus titers in zucchini and tomato were in the same magnitude order at the initial stages of infection after whitefly inoculation. However, at latter stages in zucchini, they significantly increased up to $10^{3}$-fold (DNA-A) and $10^{4}$-fold (DNA-B) (Fig. 3), reaching genomic amounts comparable with those detected in natural or experimental infections. This evolution in the titers of viral genomic DNA in zucchini is reminiscent of that from monopartite begomoviruses TYLCV and TYLCSV, where a $10^{4}$-fold increase is observed between early ( $7 \mathrm{dpi}$ ) and latter (approximately 30 to $40 \mathrm{dpi}$ ) stages in tomato (RodríguezNegrete et al. 2014).

The recent emergence of ToLCNDV-ES is associated with significant losses in cucurbit crops in the western Mediterranean, which suggests the adaptation to a new host (zucchini) and to a new geographic region (Ruiz et al. 2017; Woolhouse et al. 2005). In addition to zucchini, virulence of ToLCNDV-ES is also relevant in other cucurbit species such as melon and cucumber (Figàs et al. 2017; López et al. 2015; Ruiz et al. 2017). The different viral titers found between tomato and zucchini in the present article may be explained by a trade-off model between fitness and virulence, in agreement with a possible host shift from tomato and an adaptation process to zucchini, explaining the differential capacity of ToLCNDV-ES to infect each host (Elena et al. 2014; Longdon et al. 2015; Sacristán et al. 2005; Woolhouse et al. 2005).

\section{Acknowledgments}

L. Ruiz was supported by a research contract from IFAPA and Programa Operativo FSE de Andalucía 2007-2013, "Andalucía se mueve con Europa". This work was supported by E-RTA2013-00020-C04-01 from INIA and co-financed by the European Union through the ERDF 2014-2020 "Programa Operativo de Crecimiento Inteligente". We thank C. Zaiont for help with the statistical analysis and A. Belmonte for technical assistance.

\section{Literature Cited}

Alfaro-Fernández, A., Sánchez-Navarro, J. A., Landeira, M., Font, M. I., Hernández-Llópis, D., and Pallás, V. 2016. Evaluation of PCR and nonradioactive molecular hybridization techniques for the routine diagnosis of Tomato leaf curl New Delhi virus, Tomato yellow leaf curl virus and Tomato yellow leaf curl Sardinia virus. J. Plant Pathol. 98:245-254.

Anderson, P. K., Cunningham, A. a., Patel, N. G., Morales, F. J., Epstein, P. R., and Daszak, P. 2004. Emerging infectious diseases of plants: Pathogen pollution, climate change and agrotechnology drivers. Trends Ecol. Evol. 19:535-544.

Cleaveland, S., Haydon, D. T., and Taylor, L. 2007. Overviews of pathogen emergence: Which pathogens emerge, when and why? Pages 973-978 in: Current Topics in Microbiology and Immunology. J. A. Childs, J. E. Mackenzie, and J. S. Richt, eds. Springer, Berlin.

Debreczeni, D. E., Ruiz-Ruiz, S., Aramburu, J., Lopez, C., Belliure, B., Galipienso, L., Soler, S., and Rubio, L. 2011. Detection, discrimination and absolute quantitation of Tomato spotted wilt virus isolates using real time RT-PCR with TaqMan MGB probes. J. Virol. Methods 176:32-37.

Elena, S. F., Fraile, A., and García-Arenal, F. 2014. Evolution and emergence of plant viruses. Adv. Virus Res. 88:161-191.

Fauquet, C. M., Briddon, R. W., Brown, J. K., Moriones, E., Stanley, J., Zerbini, M., and Zhou, X. 2008. Geminivirus strain demarcation and nomenclature. Arch. Virol. 153:783-821.

Figàs, M. R., Alfaro-Fernández, A., Font, M. I., Borràs, D., Casanova, C., Hurtado, M., Plazas, M., Prohens, J., and Soler, S. 2017. Inoculation of cucumber, melon 
and zucchini varieties with Tomato leaf curl New Delhi virus and evaluation of infection using different detection methods. Ann. Appl. Biol. 170:405-414.

Fortes, I. M., Sánchez-Campos, S., Fiallo-Olivé, E., Díaz-Pendón, J., NavasCastillo, J., and Moriones, E. 2016. A novel strain of Tomato leaf curl New Delhi virus has spread to the Mediterranean basin. Viruses 8:307.

Haider, M. S., Tahir, M., Latif, S., and Briddon, R. W. 2006. First report of Tomato leaf curl New Delhi virus infecting Eclipta prostrata in Pakistan. New Dis. Rep. 11:39.

Hussain, M., Mansoor, S., Iram, S., Zafar, Y., and Briddon, R. W. 2004. First report of Tomato leaf curl New Delhi virus affecting chilli pepper in Pakistan. Plant Pathol. 53:794.

Ito, T., Sharma, P., Kittipakorn, K., and Ikegami, M. 2008. Complete nucleotide sequence of a new isolate of Tomato leaf curl New Delhi virus infecting cucumber, bottle gourd and muskmelon in Thailand. Arch. Virol. 153:611-613.

Juárez, M., Tovar, R., Fiallo-Olivé, E., Aranda, M. A., Castillo, P., Moriones, E., and Navas-Castillo, J. 2014. First detection of Tomato leaf curl New Delhi virus infecting zucchini in Spain. Plant Dis. 98:857.

Kanakala, S., Jyothsma, P., Shukla, R., Tiwari, N., Veer, B. S., Swarnalatha, P., Krishanareddy, M., and Malathi, V. G. 2013. Asymmetric synergism and heteroencapsidation between two bipartite begomoviruses, Tomato leaf curl New Delhi virus and Tomato leaf curl Palampur virus. Virus Res. 174:126-136.

Kuan, C. P., Huang, H. C., Chang, C. C., and Lu, Y. L. 2012. TaqMan real-time PCR for detection and quantitation of Squash leaf curl virus in cucurbits. J. Virol. Methods 179:367-372.

Kumar, Y., Hallan, V., and Zaidi, A. A. 2008. Molecular characterization of a distinct bipartite begomovirus species infecting tomato in India. Virus Genes 37:425-431.

Liu, W., Zhao, X., Zhang, P., Mar, T. T., Liu, Y., Zhang, Z., Han, C., and Wang, X. 2013. One step real-time RT-PCR assay for the quantitation of Wheat yellow mosaic virus (WYMV). Virology 10:173.

Longdon, B., Hadfield, J. D., Day, J. P., Smith, S. C. L., McGonigle, J. E., Cogni, R., Cao, C., and Jiggins, F. M. 2015. The causes and consequences of changes in virulence following pathogen host shifts. PLoS Pathog.11:e1004728.

López, C., Ferriol, M., and Picó, M. B. 2015. Mechanical transmission of Tomato leaf curl New Delhi virus to cucurbit germplasm: Selection of tolerance sources in Cucumis melo. Euphytica 204:679-691.

Mansoor, S., Zafar, Y., and Briddon, R. W. 2006. Geminivirus disease complexes: The threat is spreading. Trends Plant Sci. 11:209-212.

Maruthi, M. N., Rekha, A. R., Cork, A., Colvin, J., Alam, S. N., and Kader, K. A. 2005. First report of Tomato leaf curl New Delhi virus infecting tomato in Bangladesh. Plant Dis. 89:1011.

Mason, G., Caciagli, P., Accotto, G. P., and Noris, E. 2008. Real-time PCR for the quantitation of Tomato yellow leaf curl Sardinia virus in tomato plants and in Bemisia tabaci. J. Virol. Methods 147:282-289.

Mizutani, T., Daryono, B. S., Ikegami, M., and Natsuaki, K. T. 2011. First report of Tomato leaf curl New Delhi virus infecting cucumber in Central Java, Indonesia. Plant Dis. 95:1485.

Mnari-Hattab, M., Zammouri, S., Belkadhi, M. S., and Bellon, D. 2015. First report of Tomato leaf curl New Delhi virus infecting cucurbits in Tunisia. New Dis. Rep. 31:21.

Monci, F., Sánchez-Campos, S., Navas-Castillo, J., and Moriones, E. 2002. A natural recombinant between the Geminiviruses Tomato yellow leaf curl Sardinia virus and Tomato yellow leaf curl virus exhibits a novel pathogenic phenotype and is becoming prevalent in Spanish populations. Virology 303:317-326.

Moriones, E., Arnó, J., Accotto, G. P., Noris, E., and Cavallarin, L. 1993. First report of Tomato yellow leaf curl virus in Spain. Plant Dis. 77:953.

Navas-Castillo, J., Fiallo-Olivé, E., and Sánchez-Campos, S. 2011. Emerging virus diseases transmitted by whiteflies. Annu. Rev. Phytopathol. 49:219-248.

Padidam, M., Beachy, R. N., and Fauquet, C. M. 1995. Tomato leaf curl geminivirus from India has a bipartite genome and coat protein is not essential for infectivity. J. Gen. Virol. 76:25-35.

Panno, S., Iacono, G., Davino, M., Marchione, S., Zappardo, V., Bella, P., Tomassoli, L., Accotto, G. P., and Davino, S. 2016. First report of Tomato leaf curl New Delhi virus affecting zucchini squash in an important horticultural area of southern Italy. New Dis. Rep. 33:6.

Péréfarres, F., Hoareau, M., Chiroleu, F., Reynaud, B., Dintinger, J., and Lett, J. M 2011. A novel synthetic quantification standard including virus and internal report targets: Application for the detection and quantification of emerging begomoviruses on tomato. Virol. J. 8:389.

Pratap, D., Kashikar, A. R., and Mukherjee, S. K. 2011. Molecular characterization and infectivity of a Tomato leaf curl New Delhi virus variant associated with newly emerging yellow mosaic disease of eggplant in India. Virol. J. 8:305.

Rodríguez-Negrete, E. A., Sánchez-Campos, S., Cañizares, M. C., Navas-Castillo, J. Moriones, E., Bejarano, E. R., and Grande-Pérez, A. 2014. A sensitive method for the quantification of virion-sense and complementary-sense DNA strands of circular single-stranded DNA viruses. Sci. Rep. 4: Article 6438. doi: 10.1038/ srep06438

Ruiz, L., Janssen, D., Martin, G., Velasco, L., Segundo, E., and Cuadrado, I. 2006. Analysis of the temporal and spatial disease progress of Bemisia tabacitransmitted Cucurbit yellow stunting disorder virus and Cucumber vein yellowing virus in cucumber. Plant Pathol. 55:264-275.

Ruiz, L., Simón, A., Velasco, L., García, M. C., and Janssen, D. 2015. First report of Tomato leaf curl New Delhi virus infecting tomato in Spain. Plant Dis. 99: 894.

Ruiz, L., Simón, A., Velasco, L., and Janssen, D. 2017. Biological characterization of Tomato leaf curl New Delhi virus from Spain. Plant Pathol. 66:376-382.

Sacristán, S., Fraile, A., Malpica, J. M., and García-Arenal, F. 2005. An analysis of host adaptation and its relationship with virulence in Cucumber mosaic virus. Phytopathology 95:827-833.

Tiwari, A. K., Sneshi, S. K., Khan, M. S., Sharma, P. K., Raj, S. K., and Rao, G. P. 2012. Molecular detection and identification of Tomato leaf curl New Delhi virus associated with yellow mosaic and leaf curl disease of Luffa cylindrica in India. Indian Phytopathol. 65:80-84.

Venkataravanappa, V., Lakshminarayanareddy, C. N., Jalali, S., and Krishnareddy, M. 2015. Association of Tomato leaf curl New Delhi virus DNA-B with Bhendi yellow vein mosaic virus in okra showing yellow vein mosaic disease symptoms. Acta Virol. 59:125-139.

Woolhouse, M. E. J., Haydon, D. T., and Antia, R. 2005. Emerging pathogens: The epidemiology and evolution of species jumps. Trends Ecol. Evol. 20:238-244.

Yazdani-Khameneh, S., Aboutorabi, S., Shoori, M., Aghazadeh, A., Jahanshahi, P., Golnaraghi, A., and Maleki, M. 2016. Natural occurrence of Tomato leaf curl New Delhi virus in Iranian cucurbit crops. Plant Pathol. J. 32:201-208. 